\title{
Nelson Mandela e Eduardo Mondlane: discursos do Eu ao espelho repartido da diáspora protestatária moderna
}

\author{
Maria Manuela Jales C. De Araújo \\ Universidade de Lisboa
}

RESUMO: ESTE ARTIGO TRATA DE UM DIÁLOGO INTERTEXTUAL ENTRE AS AUTOBIOGRAFIAS DE NELSON MANDELA E DE EDUARDO MONDLANE COM AS ESCRITAS PROTESTATÁRIAS AFRO-AMERICANAS, NUM CAMPO TEMÁTICO REGULADO PELOS CONCEITOS DE CENTRO E DE PERIFERIA.

ABSTRACT: THIS ARTICLE IS ABOUT A INTERTEXTUAL DIALOGUE BETWEEN NELSON MANDELA'S AND EDUARDO MONDLANE'S AUTOBIOGRAPHIES WITH THE AFROAMERICAN AUTOBIOGRAPHICAL TEXTS, EXPLORED IN A THEMATIC FIELD REGULATED BY THE CONCEPTS OF CENTER AND PERIPHERY.

PALAVRAS-CHAVE: DIÁSPORA DISCURSIVA - ESTÉTICA DE RESISTÊNCIA - MONOLINGUISMO COLONIALISTA E ANTROPONIMIA

KEY-WORDS: DISCOURSIVE DIASPORA - AESTHETIC OF RESISTANCE - MONOLINGUISM AND ANTHROPONIMIA 
s autobiografias de Eduardo Mondlane e de Nelson Mandela são discursos do Eu ao espelho repartido da diáspora protestatária moderna, textos marcados por uma estética de resistência, produzida na luta contra o etnocentrismo colonial. Pela razão apontada, serão convocados a dialogar entre si, e em contraponto com a Literatura de Escravos, até Frederick Douglass, bem como com a linha de líderes políticos que ele inicia e que se estende até Martin Luther King. Propõe-se como linha temática de investigação a observação do Nome Humano Individual nas narrativas em apreço, por este se configurar um elemento de diagnose social e cultural, susceptível de ilustrar e problematizar situações de centro e de periferia, partindo do pressuposto teórico de que deter um lugar devidamente localizado na periferia não é estar na marginalidade.

O processo de reconstituição das identidades individual e social, em que o Nome Humano Individual se tem apresentado como símbolo do descentramento errante a que foi submetido o indivíduo escravo, contingência que vive na memória recente e longínqua que o sujeito tem de si próprio, encontra eco nas autobiografias contemporâneas de Nelson Mandela e de Eduardo Chivambo Mondlane.

Num abreviado percurso pela literatura afro-americana nos Estados Unidos, no seu início, se "Bars Fight", o único poema de Lucy Terry (1724-1821), circulou oralmente durante aproximadamente cem anos antes da sua primeira publicação, em 1855, e é considerado o texto inaugural das letras afro-americanas, o poema "An Evening Thought: Salvation by Christ, with Penitential Cries", de Jupiter Hammon (1711-1790/1806), com a sua publicação em 1760, celebrizou o seu autor, considerado o primeiro versificador publicado na história da literatura afro-americana. Posteriormente, em 1778, o escritor dirige um poema de 21 quadras àquela que foi considerada a primeira autora afroamericana de reputação internacional, "An Address to Miss Phillis Wheatly".

Apesar de ambos os textos estarem ainda imbuídos de uma moral religiosa assimilacionista, em que a tónica é "salvação espiritual", em vez de "resistência política", o que é certo é que Hammon contribui já, de alguma forma, para uma aproximação da linha de protesto social, ao invocar episódios bíblicos, aturadamente insinuadores da igualdade humana.

Embora os nomes mencionados se destaquem como autores de uma escrita lírica de intenção rimática sistemática, os seus escritos assumem, no entanto, 
contornos de texto autobiográfico. O Sujeito Poético, autoral, implica-se de forma identitária no referente poético, junção plural que o pronome pessoal We torna clara, no registo grafado de vivências espirituais ou terrenas que, por serem de índole colectiva, mostram como o indivíduo se auto-representa por identificação com os outros, o seu grupo humano de pertença.

No entanto, o primeiro texto autobiográfico escrito em prosa é uma narrativa de cativeiro, que surge em 1760, e se intitula Narrative of the Uncommon Sufferings and Surprizing Deliverance of Briton Hammon. ${ }^{1}$

Em 1789, The Interesting Narrative of the Life of Olaudah Equiano, or Gustavus Vassa, the African, Written by Himself foi considerado o protótipo autobiográfico de maior êxito durante todo o século XVIII, com a particularidade de inaugurar uma escrita independente, isto é, menos dirigida por escritores e editores brancos. Por contraste com a projecção internacional que ganhou a narrativa de Equiano, menciona-se apenas a quase imperceptível autobiografia de Venture Smith (1729?-1805), publicada em 1798, A Narrative of the Life and Adventures of Venture, $A$ Native of Africa. Ambos os autores, oriundos de reinos africanos situados na costa ocidental, se referem à sua ascendência real, assim como ao corte violento com a sua linhagem dinástica de sucessão.

No que diz respeito ao século XIX, a quantidade de narrativas de escravos que emerge nesse período mostra que esse é um século literariamente fértil, tendo esse género de relatos de vida continuado a surgir no século XX, quer na forma canónica de primeira pessoa, quer em forma de romance na terceira pessoa, contudo, de índole autobiográfica.

Assim, se o nome de William Wells Brown (1814?-1884) é um marco literário importante nas letras do século XIX, às quais também se juntam os nomes de Josiah Henson e de Henry Bibb, as autobiografias de Harriet Jacobs (1813-1897) e de Frederick Douglass (1818-1895) são dois marcadores principais do século em menção, na autobiografia afro-americana.

A Literatura de Escravos acima referida são escritos do Eu que relevam a impossibilidade de escolha do Nome Humano Individual, a anulação da sua descendência familiar, bem como do local de nascimento, situação de aniquilamento em que a tradição genealógica africana se foi perdendo ao longo dos

1 Para acesso ao titulo completo deste texto, veja-se LAUTER, Paul (ed.). The Heath Anthology of American Literature, 4 th. ed., v. 1. Boston, New York: Houghton Mifflin Company, 2002, p. 1.102. 
tempos, e ao escravo lhe foram sendo impostos os diversos Nomes dos seus senhores, que o registavam como bem de sua pertença, comprado, susceptível de ser leiloado e doado como herança.

A perda do Eu, revelada na instável contingência a que estava votado o nome dos escravos, situação que declara um significado social de inexistência, vem a ser reparada pelo texto autobiográfico afro-americano: o Eu grafado liberta um grito de auto-afirmação, encorajado pela Modernidade americana, que elegeu Narciso como seu símbolo preferencial. Assim, a autobiografia afro-americana veio a consagrar-se como facto cultural da Modernidade - instituído como tradição literária, é uma moderna tradição que faz a recuperação do Eu perdido. Desse modo, a literatura em menção faz a representação de dois momentos que, antagonicamente, se implicam: o período da escravatura, aniquilador do Eu, e o período que acarinha e corporiza o espírito da designada Emancipation Proclamation, em que se foi operando o resgate da identidade perdida, na emergência do Eu que, pela palavra escrita, ganhou voz.

A voz de que se fala é a voz que lutou pelo seu reconhecimento, publicamente firmada pela oratória política, celebrizada por Frederick Douglass (18181895) e por Martin Luther King Jr. (1929-1968), dois marcos importantes de uma linha contínua de líderes políticos, que integrou Booker T. Washington (1856-1915), Marcus Garvey, numa versão mais extremada do racialismo negro (1887-1940), e William Edward Burghardt Du Bois (1868-1963).

Essa linha de líderes políticos contemporâneos, traçada nas suas próprias autobiografias, é um corpus literário em que dialoga a contestação ideológica, alargando, sem fim, as zonas literárias da diáspora política afro-americana. $\mathrm{O}$ mapa geográfico dessa interactiva escrita autobiográfica protagoniza a crítica ao ideário colonial moderno, dentro e fora dos Estados Unidos, configurada no discurso anticolonial, em que o indivíduo negro deixa de ser "objecto de discurso" para se afirmar como "sujeito e objecto de discurso".

Proposta como paradigma da escrita autobiográfica afro-americana, a discursividade irreverente e contestatária dos textos de Eduardo Mondlane e de Nelson Mandela revela, como pontos de semelhança, o facto de ter crescido dentro da tradição religiosa protestante, bem como de ter sofrido a influência dos mesmos líderes políticos, ou seja, de algumas figuras proeminentes do Renascimento Negro e, no caso de Eduardo Mondlane, muito especialmente, do círculo científico de Chicago, pólo intelectual africanista. 
Dos mencionados políticos africanos, salienta-se o facto de Eduardo Mondlane, segundo a tese defendida por Silvério Pedro Eugénio Samuel², ter sido formado, nos Estados Unidos, dentro da tradição liberal americana, o que pode conferir maior pertinência ao paradigma estabelecido.

Nas narrativas memorialistas de Mandela e de Mondlane o percurso do Nome é marcado, de maneira ambivalente, quer pela força inalterável da tradição, quer pelo poder normalizador da Modernidade, definida como racional, científica, ocidental e, no presente contexto, também colonial. A interdependência dessas duas forças dinâmicas, no processo de construção das identidades culturais e sociais dos indivíduos aqui implicados, deve-se, sobretudo, à viagem voluntária do campo para a cidade, do colmo para o zinco, da palhota para a barraca, até chegar à telha e ao betão; deve-se ao contacto dos sujeitos africanos com a vivência urbana ocidentalizada, e dominada pelo colonialismo, verificando-se, em ambas as narrativas, uma construção genealógica complexa, descrita com pormenor, reveladora de uma estrutura linhagística de que o Eu é representante colectivo, e da qual ele se mostra brioso, ou mesmo glorioso.

Nelson Mandela dá início à sua autobiografia começando por afirmar a importância do Nome Humano Individual na sociedade tradicional Xhosa, a nação da qual é oriundo: "Apart from life, a strong constitution and an abiding connection to the Thembu royal house, the only thing my father bestowed upon me at birth was a name, Rolihlahla" (MANDELA, 2002, v. I, p. 3).

No entanto, se Mandela, logo no princípio da obra, parte que dedica ao relato da sua infância no campo, se refere à importância do nome Xhosa que lhe atribuído à nascença pelo pai, esmiuçando o seu significado, ao explicar seu sentido literal e coloquial, de igual modo ele releva o facto de o nome inglês Nelson the ter sido colocado no primeiro dia de escola, isto é, pela administração colonial, concluindo: "My more familiar English or Christian name was not given to me until my first day of school. But I am getting ahead of myself" (MANDELA, 2002, v. I, p. 3).

Por outro lado, na narrativa de memórias intitulada Chitlango, filho de chefe, ao Eu protagonista é transmitida, desde cedo, a importância do nome que herda à nascença, relevância essa que aparece bem marcada numa das conversas que

2 Veja-se SAMUEL, Silvério Pedro Eugénio, 2003. 
Chitlango tem com a sua mãe, em que a elocução desta se faz através de um discurso metafórico, orientado para a acção física do quotidiano doméstico:

- Mamã, a escolha do nome tem importância?

- Chitlango, olha para esta panela de ferro que o teu pai comprou nos brancos. Tem uma tampa e em cima da tampa, uma pega. Meu filho, um nome, é a pega em que os deuses agarram para manejar a tampa da nossa vida. Alguns nomes fazem-lhes medo, outros sorriem-lhes, outros ainda impõem-lhes respeito. A avó disse-te que o teu nome é querido dos deuses. Um nome querido dos deuses é uma bênção. (KHAMBANE e CLERC, 1990: 53)

O nome Eduardo Chivambo Mondlane segue um percurso idêntico ao do nome Nelson Mandela. Os dois sujeitos nomeados, embora detentores de identidades étnicas diferentes, têm em comum não só o facto de as suas culturas de origem derivarem do grande tronco Bantu, mas também de os dois indivíduos terem sido sujeitos ao mesmo fenómeno de conformização linguística, pela imposição de uma língua de colonização, ainda que por diferentes países colonizadores.

Eduardo Mondlane, apesar da descendência directa Zulo dos seus pais, afirma ser Tsonga: "Eu sou totalmente um Tsonga" (apud MANGHEZI, 2001: 64), sujeito falante da língua-mãe Changane. Nelson Mandela pertence ao povo Thembu, que faz parte da nação Xhosa, sendo sujeito falante da língua Xhosa. Mondlane, referindo-se aos diferentes contextos de colonização, Moçambique e a África do Sul, a propósito da obra Here is the Veld, de Attilio Gatti, a qual criticou, por carta, com Janet Mondlane, afirma:

Lembra-te de que eu próprio não sou cidadão sul-africano. Sou cidadão português. No meu país não temos leis de segregação... Eu farei tudo o que puder para lutar pelos direitos do meu povo no meu próprio país, onde ainda temos muito a fazer para melhorar a sorte da maioria do meu povo, que não tem educação. (apud MANGHEZI, 2001: 64)

Assim, melhor se percebe que a permitida cidadania de Mondlane, tal como a de Mandela, ao implicar o trânsito do espaço rural, tradicional, para o espaço urbano, moderno, tivesse que ser assinalada com um nome próprio 
europeu, obrigatório e, na maior parte das vezes, posto fora da possibilidade de escolha, quer do sujeito nomeado, quer de sua família.

Nas designadas Províncias Ultramarinas do Estado Português, sobretudo nos meios rurais, era prática corrente dos funcionários da Administração Civil alterar o nome de nascimento das crianças pertencentes às culturas autóctones. No momento do seu registo, para Assento de Nascimento, o nome colocado no seio da cultura-mãe era, normalmente, modificado de forma aleatória, por fazer parte de um sistema linguístico estranho ao monolinguismo colonialista. Também acontecia que, à falta de outro, o nome próprio colocado aos sujeitos em causa fosse inspirado no nome bíblico do eleito Santo do Dia, sendo só depois autorizada a permanência dos nomes herdados à nascença. $\mathrm{O}$ primeiro contacto com a nova fórmula oficial de identificação era feito na escola.

Se a autobiografia de Nelson Mandela confere visibilidade à instituição estatal escola, como estrutura impositiva de um saber ditado pela ideologia de uma minoria dominante, onde o exercício repressor, conducente à desindividualização, começa logo por se fazer operar a partir da assimilação forçada de um nome, também o texto de Eduardo Mondlane nos mostra, na discursividade das vozes que representa, a mesma perspectiva castradora de singularização humana operada pela escola.

Em ambos os textos, a escola colonial surge como órgão de poder desestruturador do nome original do sujeito, ideador do primeiro nome, dentro do mesmo espírito colonialista que motivou a secundarização do nome de nascimento, processo que traduz uma inserção periferizante da cultura de pertença dos sujeitos, a aculturar-se ao sistema silenciador em causa.

As estratégias em questão, historicamente discriminatórias, tinham como objectivo conduzir o indivíduo à perda do seu lugar específico, à anulação da sua diferença, lançando a confusão mental e iniciando um processo de disrupção identitária, desencadeado no Nome, mas em que, progressivamente, o sujeito se vai confrontando com outros actos de desvalorização humana, deliberados em função da cor da sua pele, anuladores das línguas-mãe de África, das suas sociedades, das suas culturas, das suas nações, dos seus povos, dos seus clãs familiares, dos seus impérios, da sua história.

O texto memorial de Mondlane traz para a clareira luminosa da escrita um Eu que, a priori, parece perder o seu centro, na ânsia de querer apreender e 
compreender uma nova lógica de pensamento, estruturadora da Razão imperante que o segrega. Mondlane manifesta vontade de adquirir um outro conhecimento, o do mundo dos molungos, dos brancos, que pretendem sentálo no banco do aprendente submisso, e ao qual só poderá aceder se aceitar os respectivos preceitos impostos. As condicionantes de acesso ao mundo dos brancos recordam, em termos simbólicos, a viagem iniciática antiga - neste caso, a viagem é o trânsito para a Modernidade Ocidental, e o seu herói passará por uma entrada moderna ritualizada, cuja iniciação se faz através da ditadura do "novo", um novo nome, um código de acesso e de aceitação, não reconhecido, no entanto, pela competência linguística do sujeito em causa, nem pelas suas matrizes culturais, igualmente sem significado dentro do seu universo sagrado, mas que ele, assimetricamente, deseja compreender.

$\mathrm{O}$ ponto de vista acima verbalizado é textualmente dramatizado, de forma explícita, no diálogo estabelecido entre Chitlango e o seu mestre pastor, Madjerimane, que, após sua contextualização, se transcreverá. No decorrer do referido diálogo, Chitlango revela a Madjerimane a enorme vontade de partir da sua aldeia, em demanda da cultura luzente do branco, do lugar distante, onde a forma das casas fere a concertada unidade do círculo cósmico ${ }^{3}$.

Aos olhos do seu educador, Chitlango envereda por um caminho que trai os princípios reguladores da ordem tradicional de entre eles, o que explicitamente está contido na advertência seguinte: "Tens de falar a língua dos brancos" (KHAMBANE e CLERC, 1990: 102). Se Chitlango concretizar o desejo manifestado, e segundo as regras da tradição, terá de renunciar ao nome que, comunitariamente, representa e personifica, o qual tem a obrigação de honrar, pois sua mãe, desde cedo, lhe incute a responsabilidade de honrar o nome que herdou: "- Chitlango, honra o nome que tens" (KHAMBANE e CLERC, 1990: 13).

Chitlango arrisca procedimentos que não correspondem, de todo, às expectativas familiares e comunitárias, ao questionar aspectos da sua própria cultura, embora o faça, no seu ponto de vista, para melhorar a vida do seu espaço de pertença, rebeldia que o coloca no papel de africano que se propõe a qualificar, inovar, modernizar a própria tradição cultural africana, revelando um discernimento não comum ao pensamento dos seus aldeãos.

3 Cf. KHAMBANE e CLERC, 1990, p. 43. 
O desejo de implantar novas leis na sua aldeia, mexendo assim na estrutura de um passado imodificável, começa já por ser indiciador de um processo de transformação pessoal, vital, que compromete o lugar herdado de chefe tradicional, liderança destinada, que converte em liderança escolhida, ou seja, o chefe tradicional caminha na direcção do futuro líder político nacional, experiência fundamental que foi tomando forma, e cresceu, dentro da sua vivência directa do divino, nas missões protestantes onde sempre estudou, em Moçambique, na África do Sul e nos Estados Unidos.

Chitlango ficou impressionado com a comunidade dos pastores em Niarangole, com a forma dura como foi recebido e iniciado nas suas leis, com o facto de haver fome e, segundo a tradição, só as mulheres poderem trabalhar nos campos, enquanto aos homens competia, estritamente, o manejo das armas. ${ }^{4}$ Vai-se sentindo perplexo com o que vai descobrindo, um mundo de regras cruéis e generosas, heróicas e cobardes, começando, assim, a sua primeira indagação existencial, em que o Eu se pergunta em que mundo vive, e "Como conciliar estes contrários?" (KHAMBANE e CLERC, 1990: 101). Chitlango contraria o conformismo de Madjerimane, declarando-lhe: "- Pois bem Madjerimane! Eu vou compreender [o mundo dos brancos] e ao mesmo tempo continuar a ser um verdadeiro Africano" (KHAMBANE e CLERC, 1990: 102).

Eduardo Mondlane mostra que, apesar da sua assumida identidade Tsonga, da identificação sentida com a sua gente, a consciência de que era preciso mudar foi germinando, em si, desde então, motivando a reorientação do seu protagonismo, que envolveu a renúncia à tranquilidade fundamentada no hábito, levando-o, em consequência, mais longe, quando decidiu lutar com as imposições colonialistas, tendo-se submetido para poder conhecer e, posteriormente, regressar a casa, para libertar e modernizar o seu país.

Chivambo não se conforma com a alienante convicção de Madjerimane, "- $\mathrm{O}$ que é que queres Mudar Chilango? Nós somos pretos. Vivemos como pretos, com as nossas regras...", e sem trair a sua cultura, manifesta o desejo de partir, sem, contudo, deixar de ser "[...] um verdadeiro africano" (KHAMBANE e CLERC, 1990: 102). A sua posição não é compreendida pelo mestre que o inicia na arte da pastagem, pelo que Madjerimane lhe responde evasivamente: “[...]- Basta Chitlango. Vai à escola. Põe um chapéu e uma

4 Cf. KHAMBANE e CLERC, 1990, cap. XII. 
camisa, sapatos e umas calças. Ficarás bonito e vais-te chamar Delfim ou Maomede, como os molungos, como os brancos. Passe bem, Maomed Delfim!" (KHAMBANE e CLERC, 1990: 103).

Assim, a instituição escola, dentro do contexto colonialista em foco, revela ser o primeiro elemento perturbador do inicial mundo de referências de ambos os autores, desordem identitária que fica assinalada com o primeiro nome, Nelson e Eduardo, símbolos de uma etapa, primeiro obstáculo a transpor, no longo e árduo percurso dos heróis em causa, e a que Nelson Mandela chamou Long Walk to Freedom.

Por contraste com a condição a que o nome individual foi sujeito nas Narrativas de Escravos Afro-americanas, em que este nunca mostrou constituirse voz presente de um passado ancestral, nos dois textos autobiográficos africanos, a constituição dos nomes Eduardo Chivambo Mondlane e Nelson Mandela revela, na coexistência do primeiro nome ocidental com o(s) nome(s) africano(s) tradicional(is), a forte evidência da palavra escrita, que não só se constitui vestígio histórico de domínio colonial, tal como o nome do escravo, mas também se apresenta como superfície visível, que anuncia uma profunda raiz histórica, escondida, mas que foi escapando à vigilância da Modernidade Ocidental, marcando a sua escrita, ainda que de forma subalternizada.

A composição mista desses nomes poderá configurar-se como símbolo de um cruzamento cultural e civilizacional assimétrico, entre Modernidade Ocidental e Tradição Africana, em que a língua do colonizador inscreve, no sistema semiológico da sua escrita, um outro sistema linguístico de vivência oral, a língua do colonizado, que embora tolerada, vive, não obstante, em situação de subordinação, pela prioridade concedida ao nome colonial, perante o qual os nomes africanos foram periferizados.

O raciocínio acima verbalizado parece ser confirmado pela seguinte asseveração de Nelson Mandela: "Africans of my generation - and even today - generally have both a Western and an African name. Whites were either unable or unwilling to pronounce an African name, and considered it uncivilized to have one" (MANDELA, 2002, v. I, p. 19).

Da mesma forma, fica igualmente esclarecida a razão pela qual foi afastado o seu nome Xhosa de nascença, Rolihlahla, que em Xhosa, no seu sentido literal, significa "arrancar o ramo de uma árvore", e no seu sentido coloquial significa "o que causa problemas" (MANDELA, 2002, v. I, p. 3), embora o 
nome africano de família, Mandela, herdado do avô ${ }^{5}$, tenha sobrevivido até aos dias de hoje, assim como, em circunstâncias especiais, o epíteto respeitoso de Madiba, nome do seu clã ${ }^{6}$.

No texto autobiográfico de Eduardo Mondlane, no prefácio da obra, o Dr. Pascoal Mocumbi esclarece que também o nome Tsonga de nascença, Chivambo, foi substituído por Chitlangou, precisamente "[...] para evitar a repressão colonial [...]” (KHAMBANE e CLERC, 1990: 3), variação onomástica que pretende iludir a vigilância do poder vigente.

Chivambo herdou um nome de alta linhagem; seu pai era regente do clã Khambane, representante de uma linha nobre de ascendência, da qual sua mãe o foi conscientizando: "- Os teus antepassados foram tão grandes senhores que reuniram e comandaram os exércitos contra o invasor Zulu, há dezenas e dezenas de anos" (KHAMBANE e CLERC, 1990: 14). O nome herdado à nascença invoca o último predecessor mais afamado do seu ramo familiar, Chitlango-oVelho, assim como outros ramos genealógicos nos quais entronca, pelo que sua mãe faz questão de lhe revelar, discriminadamente, a sua ilustre nomeada: "O último grande senhor do país, amado e respeitado - se bem que submetido aos brancos - foi Chitlango-o-Velho, que governou muito, muito tempo. Ele veio a seguir a seu pai, Psarithio, filho de Mitambuti, filho de Chipeniane, filho de Khambane, filho de Ndzovo" (KHAMBANE e CLERC, 1990: 14).

A sucessão de nomes acima transcrita transporta até ao presente narrativo uma memória longínqua, que marcou o nome completo dos sujeitos em causa. A tradição revela aqui sobreviver sob a forma de chamamento da ancestralidade, de entidades espirituais, os grandes antepassados sepultados na orla da floresta sagrada. O universo sagrado de transmissão divina de que o sucessor africano acredita ser personificação, representação do seu poder e conhecimento, rege-se por uma espécie de encarnação, de possessão linhageira, a imortalidade desejada e contida na advertência verbal da mãe a Chitlango:

- É preciso que te lembres muito bem dos nomes de todos estes grandes chefes, porque eles vivem conosco. [...]

5 Mandela, filho mais novo da Casa Ixhiba (cf. Mandela, 2002, v. I, p. 5-7).

6 Madiba era o nome de um chefe Tembu que no século XVIII reinou no Transkei, tendo dado o nome a um clã, ao qual pertence Mandela (cf. Mandela, 2002, v. I, p. 5). 
- Quando um chefe morre e se enterrou o seu cadáver, ele mesmo vai para a "Grande assembleia dos chefes mortos".

(KHAMBANE e CLERC, 1990: 14)

A Grande Assembleia dos Chefes Mortos que se reúne à sombra de uma árvore, deuses a quem todos os membros da aldeia têm de render culto e prestar contas de todos os acontecimentos importantes das suas vidas, por intermédio de um sacerdote, veículo entre os homens e o divino, e vice-versa, a quem o pai de Chitlango comunicou o nascimento do seu filho, ao qual, por regozijo dos deuses, foi posto, sem equívoco, o nome de Chivambo.

Assim, Chivambo adquire o nome de um dos deuses do clã Khambane, um dos clãs que, nas suas palavras, "[...] continua a viver e a distinguir-se [...]" (KHAMBANE e CLERC, 1990: 30), sendo eleito mbamba, "[...] a pessoa que irá estabelecer um laço entre os deuses-antepassados e o clã” (KHAMBANE e CLERC, 1990: 31), assumindo, convictamente, a sua identidade Khambane, logo na sua infância, durante a cerimónia festiva do seu clã, na capital mística dos Khambane, a orla da floresta sagrada, quando profere: "Sou um Khambane. Sou o grande Chitlango dos Khambane. Todo o clã vive em mim. Eu encarno-o" (KHAMBANE e CLERC, 1990: 23).

No entanto, a transição desse mundo tradicional africano para a progressiva vivência da moderna civilização ocidental implica, em Eduardo Mondlane, uma outra identidade, erigida dentro das várias missões religiosas e universidades, que o acolheram e onde se formou, reconhecendo-se, na multiplicidade de experiências e saberes vividos, como um ser culturalmente mestiço: “[...] Penso que foi o que me aconteceu, tal como a milhares de outros africanos. Adquiri uma compreensão suficiente da cultura ocidental para poder ser considerado um ocidental, E, no entanto, continuo a ser essencialmente africano. Não quero dizer que vou viver uma vida africana como viveram os meus pais, isso seria impossível. Mas o que sou agora é uma nova contribuição que é desejável para o tempo em que vivo" (MONDLANE apud MANGHEZI, 2001: 77).

Eduardo Mondlane começou por estudar numa escola oficial em Moçambique, dirigida pela igreja católica, mas o seu descontentamento fê-lo mudar para a escola da Missão Suiça, na aldeia de Maússe. Mais tarde, transitou para Lourenço Marques, onde continuou a estudar e a trabalhar na mesma 
missão, em que o missionário-chefe, André-Daniel Clerc, encorajador da sua autobiografia, assumiu o papel de seu pai adoptivo e guia fundamental, na continuação da sua educação. Desde então, o seu percurso passa pela Escola Metodista Americana, em Cambine, Inhambane; pela Escola Secundária da Missão Suiça, Lemana, situada no Transval Norte, e pela Universidade de Witwatersrand, em particular, ambas na África do Sul, salientando-se, ainda, o seu trajecto académico nos Estados Unidos, Oberlin College e Northwestern University. Esta última, uma universidade metodista, famosa pelos seus africanistas, onde Mondlane contactou de perto com o africanista KimballYoung e onde foi aluno de Melville J. Herskovits (1895-1963), o antropólogo fundador do primeiro programa universitário em Estudos Africanos, o qual foi considerado o pai do americanismo negro. Na altura, a Universidade do Noroeste constituía-se como satélite do centro científico e ideológico de Chicago, onde se concentrou a intelectualidade multiétnica metodista que marcou a Modernidade Americana em particular, mas também todo o mundo.

Se a identidade ocidental de Eduardo Mondlane ficou assinalada no nome Eduardo, a sua identificação com África permaneceu inscrita no sobrenome Mondlane, que o reverendo Macavi enalteceu. Nos anos 1960, de regresso ao seu país, após onze anos fora, Mondlane é recebido na igreja de Chamanculo, onde o reverendo Gabriel Macavi proferiu as boas-vindas ao Senhor Doutor Eduardo Chivambo Mondlane, doutorado nos Estados Unidos e, na altura, com funções assumidas de líder político, ao serviço da ONU.

O poema épico proferido pelo senhor Macavi eleva Eduardo Mondlane ao lugar de herói nacional, começando por exaltar a sua proveniência genealógica que, embora enraizada numa procedência menos relevada, a de Mondlane, ali entronca, conferindo, no entanto, maior ênfase a Mbingwana de Kambane ${ }^{7}$.

Desse modo, o trânsito vivencial que Eduardo Mondlane escolheu percorrer entre várias culturas veio projectar universalmente o sobrenome Mondlane, adoptado como nome de família, extensivo à sua esposa, na altura, de naturalidade americana, e filhos.

Eduardo Mondlane, quer em termos de seu suporte religioso, enquanto experiência fundamental do indivíduo que assume uma consciência messiânica, quer em termos políticos, na prática de acções intervencionistas de

7 Cf. MANGHEZI, 2001: 191-192. 
libertação dos povos oprimidos em África ${ }^{8}$, veio a constituir-se, igualmente, em um potencial líder nacional, cujos objectivos de luta mantiveram alguns pontos de contacto com os propósitos que guiaram os chefes carismáticos afro-americanos: a institucionalização de uma nova ordem, disruptora da lógica colonial.

Nesta afinidade discursiva bebe o fundamento de conferir visibilidade aos diálogos que se geraram entre as duas zonas literárias, a afro-americana e a africana, argumento que justifica a escolha das autobiografias de Nelson Mandela e de Eduardo Chivambo Mondlane, ambos líderes políticos, paradigmas da linha afro-americana, em cujas escritas o Eu é plural e eminentemente ideológico, pontos de convergência comunitária, representantes reconhecidos pelos seus povos, que neles acreditaram como gestores fidedignos de um projecto comum, um projecto nacional de transformação social e política.

As vozes que aqui se falam, em acto ilocutório do Eu, dimanam de um "topos guerreiro", que profere da margem para o centro, em rejeição das franjas da marginalidade. Por conseguinte, são textos que parecem falar a mesma língua, uma diáspora discursiva que dialoga inter-textos.

À luz da aplicação teórica dos conceitos de centro e de periferia, feita por Anthony Smith, vale dizer que o Eu afro-americano, subordinado às etnias dominantes do estado colonial euro-americano, insiste em falar da periferia para o centro, onde se fizeram ouvir os líderes que afirmaram falar em seu nome. O Eu colectivo de Mondlane e o de Mandela efectivaram uma viagem dos seus centros étnicos, Changane e Xhosa, em direcção a outros centros intelectuais e políticos, também governados pelas etnias nucleares dos estados coloniais. As três situações ilocutórias do Eu mostram recusar o estatuto de minorias sociais colonizadas, tendo lutado pela sua diferenciação cultural e nacional, contra a prepotência dos estados coloniais. Os grupos humanos aqui implicados partem de situações periféricas dessemelhantes, encontrando, não obstante, afinidades no repúdio que fazem do estatuto de marginalidade a que foram remetidos.

8 Tais como as que desenvolveu na ONU, onde apresentou um manifesto político em que se lê: “[...] Primeiro que tudo, nós não estamos interessados em fazer parte de Portugal” (cf. SAMUEL, 2003: 259). 9 Utiliza-se a expressão de Roland Barthes (BARTHES, 1980: 68). 


\section{Bibliografia Activa}

KHAMBANE, Chitlango; CLERC, André-Daniel. Chitlango, filho de chefe. Trad. Maria de Lurdes Torcato e Ana Maria Branquinho. s. l. Cadernos Tempo, 1990.

MANDELA, Nelson. Long Walk to Freedom, v. I e II. Great Britain: Abacus, 2002.

\section{Bibliografia Passiva}

ANDRADE, Mário Pinto de. Origens do nacionalismo africano: continuidade e ruptura nos movimentos unitários emergentes da luta contra a dominação colonial portuguesa: 1911-1961. Lisboa: Dom Quixote, 1998.

ANDREWS, William L. (Ed.). African American autobiography: a collection of critical essays. EUA: Prentice-Hall, 1993.

BHABHA, Homi K. The location of culture. London and New York: Routledge, 2006.

BARTHES, Roland. O prazer do texto. Trad. Maria Margarida Barahona. Lisboa: Ed. $70,1980$.

CORNEVIN, Marianne. O apartheid: poder e falsificação histórica. Trad. Maria Cristina Rocha. Lisboa: Ed. 70, 1979.

DERRIDA, Jacques. O monolinguismo do outro, ou a prótese de origem. Trad. Fernanda Bernardo. Porto: Campo das Letras, 2001.

SPIVAK, Gayatri Chakravorty. Can the subaltern speak? In: ASHCROFT, Bill; GRIFFITHS, Gareth; TIFFIN, Helen (eds.). The Post-colonial studies reader. London and New York: Routledge, 1999. p. 24-28.

GATES, Henry Louis; Jr., MCKAY; Nellie, Y. (Eds.). The Norton Anthology of African American Literature. New York and London: W. W. Norton \& Company, 2004.

IRELE, Abiola F. The African imagination: literature in Africa \& the black diaspora. New York: Oxford University Press, 2001.

LAUTER, Paul (Ed.). The Heath Anthology of American Literature. 4th. ed., v. I. Boston, New York: Houghton Mifflin Company, 2002.

MANGHEZI, Nadja. O meu coração está nas mãos de um negro: uma história da vida de Janet Mondlane. Trad. Machado da Graça. Maputo: Centro de Estudos Africanos UEM e Livraria Universitária UEM, 2001.

SAMUEL, Silvério Pedro Eugénio. Pensamento político liberal de Eduardo Chivambo Mondlane. Tese apresentada à Universidade Católica Portuguesa para obtenção do grau de doutor em Filosofia. Faculdade de Filosofia de Braga, 2003.

SARACENO, Chiara; NALDINI, Manuela. Sociologia da família. Trad. Isabel Teresa Santos. Lisboa: Estampa, 2003. 
SEGALEN, Martine. Sociologia da familia. Trad. Ana Santos Silva. Lisboa: Terramar, 1999.

SMITH, Anthony D. Nações e nacionalismo numa era global. Trad. Carlos Leone. Oeiras: Celta, 1999.

TOURAINE, Alain. Crítica da Modernidade. Trad. Fátima Gaspar e Carlos Gaspar. Lisboa: Instituto Piaget, 1994. 